\title{
Geometric morphometric analysis of body-form variability in Cichlasoma minckleyi, the Cuatro Cienegas cichlid
}

\author{
Josh Trapani \\ Museum of Paleontology and Department of Geological Sciences, University of Michigan 1109 Geddes Avenue, \\ Ann Arbor, MI 48109-1079, U.S.A. (e-mail: jtrapani@umich.edu); Current address: Department of Ecology \& \\ Evolutionary Biology, University of Colorado, Boulder, CO 80309-0334, U.S.A. (e-mail: josh.trapani@ \\ colorado.edu)
}

Received 7 October $2002 \quad$ Accepted 29 July 2003

Key words: Cichlidae, polymorphism, allometry, ecomorphology, size, shape

\begin{abstract}
Synopsis
In this study, I investigate body-form variability in the trophically polymorphic Cuatro Cienegas cichlid, Cichlasoma minckleyi. I use geometric morphometrics to assess and compare size, shape, and allometric patterns within and between dental morphs (distinguished by differences in pharyngeal bones and papilliform or molariform dentitions). I find that dental morphs do not differ significantly in size, shape, or allometric slopes, but do differ in allometric intercepts; thus, dental morphs exhibit different patterns of body-form variability. Within each morph, body-form varies between more fusiform 'piscivores' and deeper-bodied dietary generalists. However, papilliform individuals show a continuous distribution of body-forms, whereas molariform individuals exhibit a discontinuity. I compare results from geometric analyses with those from a traditional (distance-based) morphometric analysis, finding that geometric techniques more clearly recognize discontinuities in shape. Finally, I suggest explanations for observed differences in body-form variability between dental morphs, concluding that the best explanation hinges on the relative importance of genetic and environmental factors in influencing body-form.
\end{abstract}

\section{Introduction}

Intraspecific morphological polymorphisms have been the subject of widespread study. Polymorphism may depend upon environmental input, may be entirely under genetic control, or may result from gene-environment interaction (Clark 1976); thus, polymorphisms may provide systems for studying the way genotype and environment interact to produce the phenotype. Genetic control of polymorphism may itself evolve, due to the modular nature of many gene networks (Weiss \& Fullerton 2000, Abouheif \& Wray 2002). Polymorphism also features prominently in discussions about speciation and adaptive radiation, often as an intermediate step during sympatric lineage divergence (Rosenzweig 1978, West-Eberhard 1986, Meyer 1993, Wimberger 1994, Schluter 1996, Smith \& Skulason 1996). This latter point raises the interesting but often neglected question of how separate species may be distinguished from a single polymorphic species, a distinction that becomes even more difficult when populations hybridize (Robinson \& Schluter 2000).

In the case of the endemic cichlids of the Cuatro Cienegas Basin (Coahuila, Mexico), interest in the number of species present (i.e. whether the cichlids constitute a single polymorphic species or a small 'species flock') and variability within them has continued for more than 30 years. Early workers in the Cuatro Cienegas Basin recognized four cichlid morphs, which they equated with species (Taylor \& Minckley 1966, Minckley 1969, LaBounty 1974). Two morphs were distinguished by characters of the pharyngeal bones and possession of molariform or papilliform dentition (Figure 1(a)); two others by body-form. In particular, some fish of each dental morph were thought 
(a)

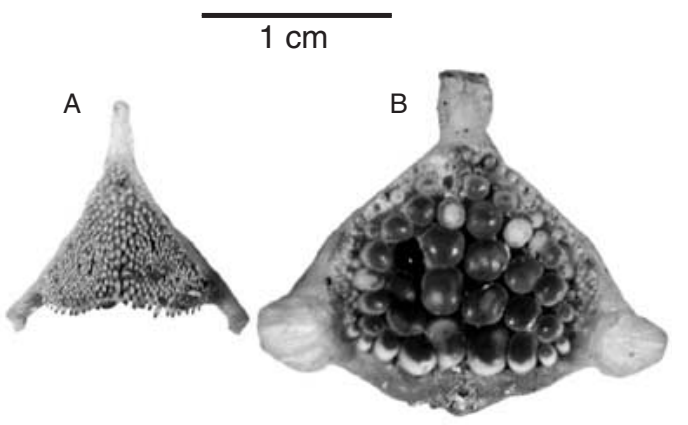

(b)

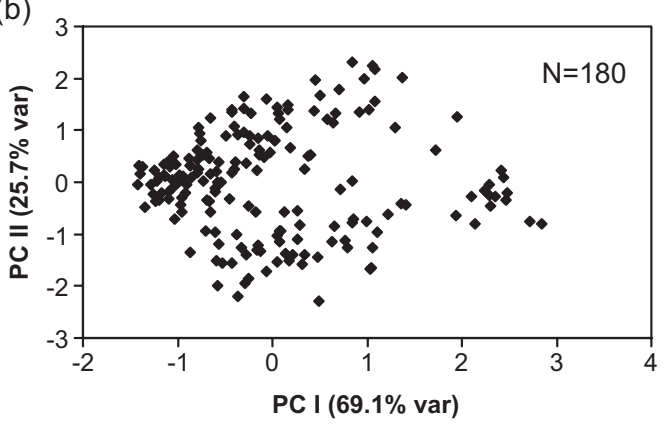

Figure 1. (a) Lower pharyngeals (fused fifth ceratobranchials) of papilliform (A: UMMZ 198937-1: S.L. $=112.5 \mathrm{~mm}$ ) and molariform (B: UMMZ 198947-1: S.L. = $121.6 \mathrm{~mm}$ ) Cuatro Cienegas cichlids. Differences between morphs involve bone size, robustness, and tooth size, shape, and numbers, as well as pharyngeal musculature (not shown). (b) PCA of pharyngeal measures in 180 Cuatro Cienegas cichlids. Measurements are: 1, width at rami; 2 , width of dental area; 3 , length at symphysis; 4 , length of dental area at symphysis; 5 , number of teeth mediolaterally along back row; 6 , number of teeth anterioposteriorly along symphysis; 7 , maximum tooth width; 8 , distance taken up by four back teeth along symphysis. Analysis was performed on the correlation matrix of logged variables (tooth counts were not logged).

to be characterized by a relatively narrow body and long head. Examination of stomach contents associated these narrow-bodied fish with piscivory (LaBounty 1974, Sage \& Selander 1975).

Investigation of biochemical differences between dental morphs showed these to be minimal, and led to reconsideration of the idea that morphs constituted separate species (Kornfield \& Koehn 1975, Sage \& Selander 1975). Kornfield et al. (1982) documented nonassortative mating between dental morphs, and Kornfield \& Taylor (1983) subsequently grouped all endemic Cuatro Cienegas cichlids into a single species, Cichlasoma minckleyi, considered polymorphic both for pharyngeal apparatus and for body-form. However, consolidation into a single species on these grounds

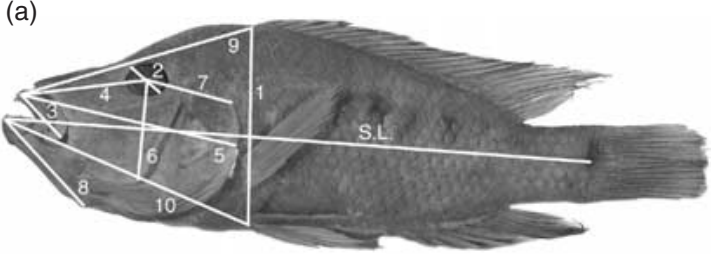

(b)

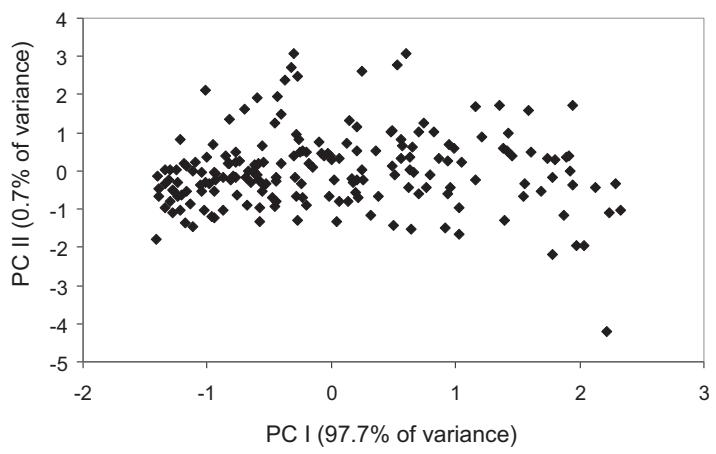

Figure 2. (a) Body-form measures for the traditional morphometric analysis. Sample was 193 Cuatro Cienegas cichlids ranging from 50 to $169 \mathrm{~mm}$ S.L. Measures are as follows: 1, body depth pectoral to pelvic fin; 2 , eye width; 3 , upper jaw length; 4 , snout length; 5, head length; 6 , cheek depth; 7, postorbital length; 8, lower jaw length; 9, predorsal length; 10, prepelvic length; 11, postorbital head width (not shown); 12, maximum head width (at opercules, not shown). (b) Results of PCA of these measures; scores on the first two components.

did not satisfy some workers (e.g., Minckley 1984, R.R. Miller, personal communication). Regardless of the number of species, disagreement also exists as to whether piscivores constitute a discrete morphotype or simply reflect an extreme in a continuous range of variation (e.g., Sage \& Selander 1975 vs. Kornfield \& Taylor 1983).

Part of the reason for this continuing disagreement is that morphological variability in pharyngeal dentition and body-form has not been quantitatively documented for large samples, nor has there been any investigation of possible covariation between the two sets of characters. Early work in the basin consisted mainly of qualitative assessment of variability, and most later genetic and behavioral studies either relied on this assessment or altogether ignored variability in bodyform - concentrating only on comparing molariform and papilliform individuals.

A principal component analysis (PCA) of measures related to the pharyngeal apparatus measured on a large sample (180 individuals) showed that there are two dental morphs with few intermediates (Figure 1(b); 
Trapani 2003). An analysis of variability in bodyform (Figure 2) led me to conclude that body-form varied continuously and there was no distinct narrowbodied morph (Trapani 2003). However, this analysis had several shortcomings. First, the measures chosen were primarily from the head region, and might not have detected important variability in other regions of the body. Second, the first PC accounted for so much of the variance in the data that other, more subtle features might have remained undetected. Finally, the analysis was performed on the same individuals for which pharyngeals were measured to assess variability in its characters, and thus the sample was not divided a priori based on dental morph.

The goal of this paper is to present the results of a reanalysis of body-form in C. minckleyi using the techniques of geometric morphometrics (e.g., Bookstein 1991, Rohlf \& Marcus 1993). Geometric morphometric techniques have been used in previous studies of fishes to investigate topics related to those addressed in this study, including issues of allometry (Zelditch \& Fink 1995) and comparative analysis of ontogeny (Zelditch et al. 2000), dimorphism (Hood \& Heins 2000), and variability in body-form (Walker 1996; Guill et al. 2003) and trophic morphology (Caldecutt \& Adams 1998, Albertson \& Kocher 2001, Ruber \& Adams 2001).

I use geometric morphometrics to ask whether molariform and papilliform morphs of C. minckleyi differ in size, shape, and allometric patterns. Ecomorphological theory and empirical observations on cichlids and other fishes would predict that mollusccrushing molariform fish should have deeper bodies and blunter snouts (Meyer 1987, 1990, Robinson et al. 1993, Hegrenes 2001); because all fish appear papilliform at small size, a further prediction would be that molariform fish experience a greater rate of allometric change in body-form (Meyer 1990).

I also investigate and compare patterns of bodyform variability within morphs. Piscivores should be characterized by a suite of features, including a lengthening of the preotic skull region, a decrease in the angle at which the preorbital face of the skull slopes downward, presence of elongate dentigerous and ascending processes of premaxilla, and an elongate mandible (Liem 1978), as well as more fusiform body to enhance locomotion during pursuit of evasive prey items (Webb 1984). There is no particular reason to predict either continuous or discontinuous body-form variability within dental morphs, but as this is a point of contention for C. minckleyi (e.g., Sage \& Selander 1975 vs. Kornfield \& Taylor 1983), I attempt to resolve the issue. Finally, I compare these results with those from a traditional morphometric analysis of interlandmark distances generated from the same individuals.

\section{Materials and methods}

Material used in this study comes from the collections of the University of Michigan Museum of Zoology Fish Division (UMMZ) and the Department of Biology at Arizona State University (ASU). The sample consists of 256 wild-caught and preserved individuals from localities within the Cuatro Cienegas Basin, a small $(\sim 30 \mathrm{~km} \times 40 \mathrm{~km})$ limestone basin. Localities include pozas (pools), lagunas (small lakes) and fluvial environments within this heavily karstified and hydrologically complex basin (see Minckley 1969). Potential exists for geographic variation in cichlid morphology, but uneven and temporally divergent sampling of localities makes assessment of such variation difficult, as do size differences between sampled individuals at different localities. Furthermore, it is likely that many localities are at least intermittently interconnected via underground karst connections that allow organisms to move throughout the basin. For these reasons, this study treats Cuatro Cienegas cichlids as a single genetic population and does not explicitly account for geographic variation.

Individuals were assigned to dental morph (papilliform, molariform, or unassignable) after examination of their pharyngeal apparatus (Trapani 2003). The final sample consisted of 124 papilliform, 104 molariform, and 28 unassignable individuals. The 'unassignable' sample mainly included individuals of small size (less than $\sim 30 \mathrm{~mm}$ S.L.) as well as a few larger individuals from the ASU collection from which lower pharyngeals had not been exposed or dissected. At standard lengths less than $\sim 30 \mathrm{~mm}$, all individuals appear papilliform and assignment to dental morph is problematic (Stephens \& Hendrickson 2001, Trapani 2003). Smaller individuals were included primarily to increase the size range of the sample.

Each specimen was photographed with a video camera and image collection software, and 23 landmarks were digitized (using tpsDig by F.J. Rohlf, available at http://life.bio.sunysb.edu/morph/). Landmarks are illustrated and described in Figure 3. In order to minimize size-related digitizing error, the camera was adjusted so that each fish took up about the same amount of the frame, regardless of its size. Repeated digitization 


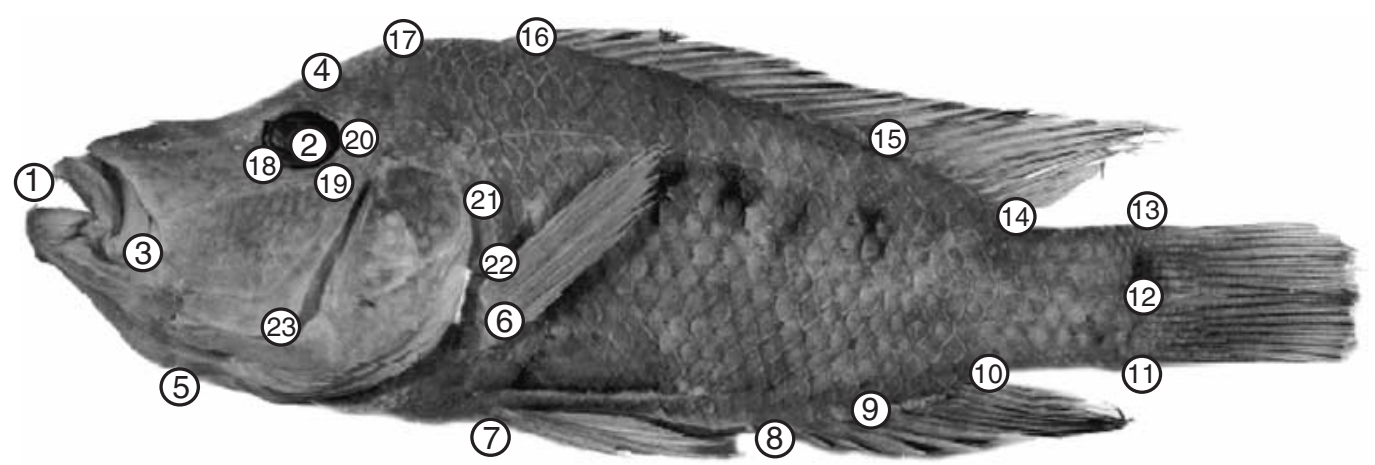

Figure 3. Landmarks used in this study. Landmarks are: 1, tip of upper jaw; 2, center of eye; 3, posterior end of upper lip; 4, posterior end of ascending process of premaxilla; 5 , posterior end of lower jaw; 6 , origin of pectoral fin; 7, origin of pelvic fin; 8 , origin of anal fin; 9, first hard fin ray, anal fin; 10, insertion of anal fin; 11, base of caudal fin; 12, center of caudal fin; 13, top of caudal fin; 14, insertion of dorsal fin; 15, first hard fin ray, dorsal fin; 16, origin of dorsal fin; 17, top of supraoccipital; 18, lacrimal-prefrontal contact at orbit; 19 , base of sphenotic at orbit; 20, top of sphenotic at orbit; 21, dorsal extent of gill cover; 22, most posterior point on gill cover; 23, point of maximum curvature on preopercle. Many osteological landmarks could be seen on preserved specimens; others (e.g., 4,5$)$ were located and marked with pins.

of the same individual resulted only in small, spherical error around each landmark.

After digitization, landmark coordinates were translated to align the centroids of each individual, rotated and rescaled to produce Procrustes shape coordinates (using CoordGen6 by H.D. Sheets, available as part of the Integrated Morphometrics Package (IMP) at: http://www2.canisius.edu/ sheets/morphsoft.html) which minimize least-squares differences between landmark alignments scaled to unit centroid size, the square root of the summed square distances from each landmark to the center of the form (Bookstein 1991).

\section{Size and shape differences between morphs}

Geometric morphometrics removes geometric scale but not shape differences associated with changes in size (i.e., allometry). Thus, I assessed significance of both size and shape differences between morphs. Significance of size (log centroid size (LCS)) differences between morphs was assessed with analysis of variance (SYSTAT 10.0). Significance of shape differences between morphs was assessed using a resamplingbased Goodall's F-test (TwoGroup6A, IMP).

\section{Allometric patterns within and between morphs}

Multivariate regression of shape (in the form of a weight matrix of partial warp scores) on size (LCS) was performed separately for each morph (tpsRegr).
Multivariate analysis of variance (MANOVA) and multivariate analysis of covariance (MANCOVA, with LCS as the covariate) were used to compare allometric slopes and intercepts of morphs, respectively (tpsRegr; see Adams \& Funk 1997 and Monteiro 1999 for more information on these and related procedures). In addition, I compared directions of allometric shape change between morphs by estimating the angle between them; these angles are compared to the range of angles that can be obtained within a morph by bootstrapping (VecCompare, IMP). Greater variability within than between morphs means that vectors of individuals in both morphs overlap to some degree, and thus indicates nonsignificant differences in direction of shape change with size in two groups.

\section{Investigation of intra-morph body-form variability}

To investigate body-form variability within and between dental morphs, I performed principal component analyses on Procrustes shape coordinates for the entire sample, and for individual dental morphs (PCAGen6b, IMP). For reasons discussed in more detail in 'Results', it was also desirable to investigate variability in morphs with the allometric (sizecorrelated) component of shape removed. There has been a great deal of discussion about how to separate size from shape in morphometric studies (e.g., Humphries et al. 1981, Bookstein et al. 1985, Bookstein 1989). Because geometric morphometrics provides a 
size variable (centroid size) uncorrelated with shape variables in the absence of allometry (Bookstein $1996 \mathrm{~b}$ ), it is possible to remove variance in shape associated with differences in size prior to ordination. For each morph, shape variables were regressed on LCS. Residuals for each individual from the regression were added to the value predicted by the regression model at a specified value of LCS (Standard6, IMP; see Zelditch et al. 2003 and also Thorpe 1975 and Lleonart et al. 2000). I chose the mean value of LCS for each morph as this value, although (as will be shown in 'Results') I could have used the pooled mean for the entire sample. I also tested to ensure that standardizing shape to different values of LCS would not alter the resulting pattern. PCA was then performed on Procrustes shape coordinates of standardized data.

\section{Comparison with traditional morphometrics}

To compare the ability of geometric and traditional distance-based morphometrics to recognize shape differences, I generated a traditional data set from the same individuals used in the geometric analyses (TmorphGen, IMP). For $\mathrm{k}>3$ landmarks, there are $\mathrm{k}(\mathrm{k}-1) / 2$ interlandmark distances $(\mathrm{n}=253$ for 23 landmarks), but there are only $2 \mathrm{k}-4$ degrees of freedom (42 in this case). For this reason, including all possible interlandmark distances does not provide any obvious advantage in terms of informational content over a data set of much lower dimensionality (Bookstein 1991, personal communication). Nonetheless, to illustrate the point and to avoid any arbitrary choices, I used all 253 distances. I performed principal component analyses on the covariance matrix of the logged data (SYSTAT 10.0).

\section{Results}

\section{Size and shape differences between morphs}

Neither size (ANOVA: $\mathrm{F}=0.0259 ; \mathrm{p}=0.8723$ ) nor body shape (Goodall's F-test: $\mathrm{F}=1.39 ; \mathrm{p}=0.1656$; 900 bootstraps) differences between dental morphs were significant.

\section{Allometric patterns within and between morphs}

Multivariate regression of shape on size demonstrated that both morphs exhibit significant allometric variation (molariform: Wilks' $\Lambda=0.0161$, $\mathrm{p}=8.660 \times 10^{-42}$; papilliform: Wilks' $\Lambda=0.0455$, $\left.\mathrm{p}=9.462 \times 10^{-40}\right)$. Patterns of allometric shape variation are shown in Figure 4. As individuals of both morphs grow larger, the most prominent changes are a shortening of the mid-body region and a lengthening of the snout region relative to the rest of the head.

Despite significant allometric variation in each morph, MANOVA results indicate that morphs do not differ in allometric slopes (Wilks' $\Lambda=0.7563$, $\mathrm{p}=0.9911$ ). This result matches with Figure 4, which shows very similar patterns of allometric variation in both morphs. Results from the comparison of direction of shape change with size are also nonsignificant (between-morph angle $=15.2^{\circ}$; within-morph angles: papilliform $=22.6^{\circ}$, molariform $=25.8^{\circ}$ ).

However, when size is held constant (MANCOVA), morphs differ significantly (Wilks' $\Lambda=0.6799$, $\mathrm{p}=5.666 \times 10^{-4}$ ) and thus exhibit different allometric intercepts. Permutation tests (1000 replicates) support the significance of the results $(p \leqslant 0.001)$. This means that shape differences between morphs reflect more than just allometric projections of size differences (Adams \& Funk 1997).

\section{Investigation of intra-morph body-form variability}

I assessed body-form variation within and between morphs using PCA of Procrustes shape coordinates (Figure 5). Because of rescaling (i.e. removal of many size effects), the first two components account for only $24.3 \%$ and $10.7 \%$ of the variance, respectively. There appears to be no discontinuity, nor any clustering by dental morph. The papilliform morph shows no group structure on this plot, whereas in the molariform morph, a group of eight individuals appear to be separated from the others (higher PC II scores). PC I is significantly correlated with LCS $\left(\mathrm{R}^{2}=0.7169, \mathrm{p}=1.4606 \times 10^{-71}\right)$ and many of the small 'unassignable' specimens are grouped on the left in the plot. This is likely due to shape variability associated with size differences.

PCA of size-standardized data (unassignable specimens excluded) is shown in Figure 6. The MANCOVA results, presented above, provide a justification for removing the allometric component of shape for this part of the analysis. When size is held constant (treated as a covariate), the two morphs exhibit significant differences. Ordination of individuals standardized to a given size allows us to visualize and try to interpret 

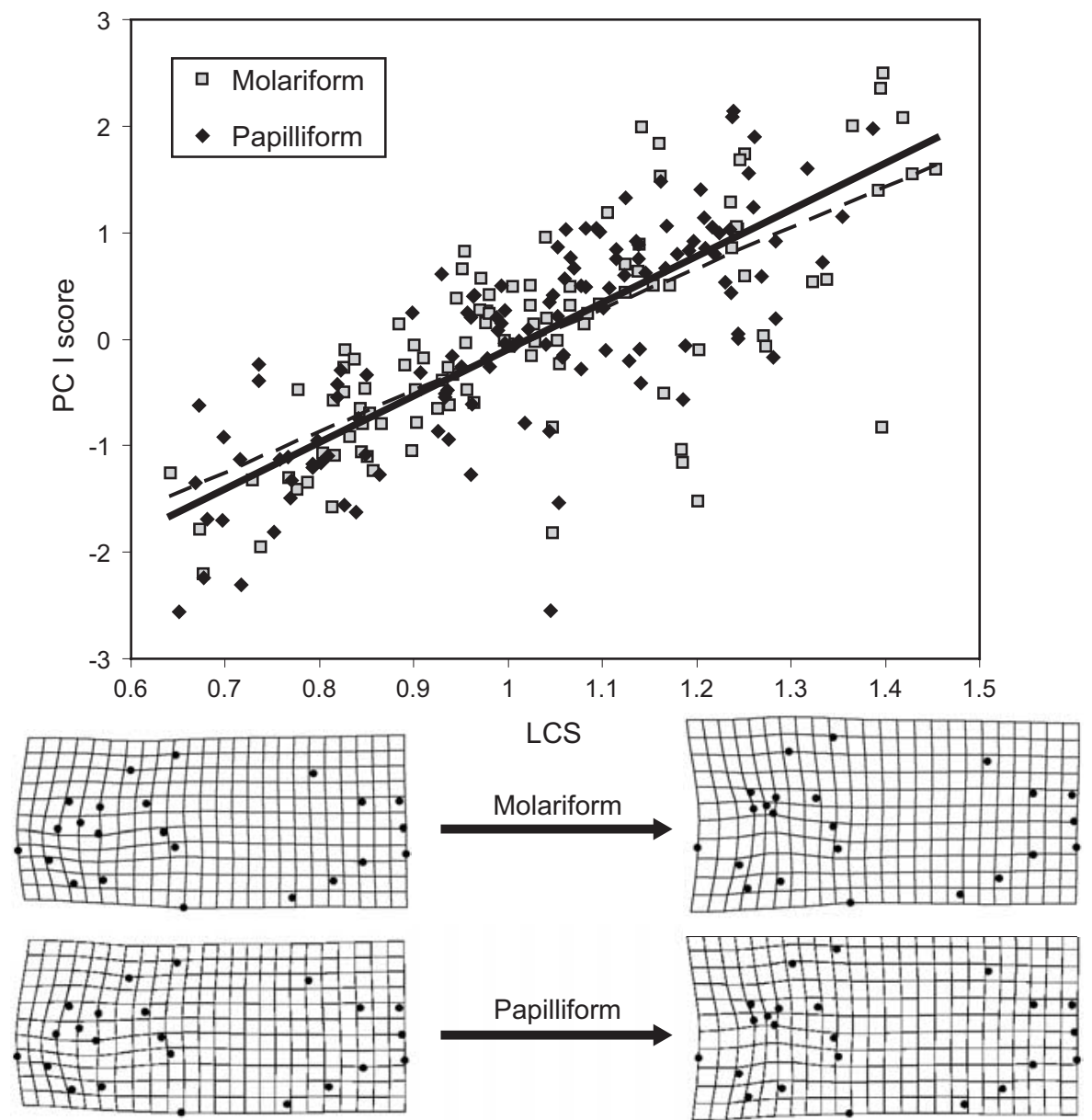

Figure 4. LCS plotted against PC I score for individuals of both dental morphs. Molariform $\mathrm{R}^{2}=0.5319, \mathrm{p}=1.6514 \times 10^{-18}$ (dotted line); papilliform $\mathrm{R}^{2}=0.6205, \mathrm{p}=1.9638 \times 10^{-27}$ (solid line). Thin-plate spline deformation grids (relative to an undeformed grid representing the consensus form of the entire sample) are shown representing small (left) and large (right) individuals of both dental morphs.

these differences. As mentioned above, I standardized individuals in each morph to have the shape they would have at that morph's mean LCS, although the fact that the morphs do not differ in slope (as shown above) means that I could have used the pooled mean of both morphs as the chosen value. In addition, I tested to ensure that standardizing at different values of LCS did not affect the results by performing PCA of individuals standardized to the minimum and maximum values for each morph. The more different the allometric trajectories of the two groups are, the more likely it is that standardization to different sizes will affect patterns observed on PCA. In this case, the pattern in Figure 6 was present regardless of the value of LCS chosen for standardization.
In Figure 6, PCs I and II account for $17.6 \%$ and $10.8 \%$ of the variance, respectively. Not surprisingly, PC I score and LCS are nearly uncorrelated $\left(\mathrm{R}^{2}=3.807 \times 10^{-10}, \mathrm{p}=0.9997\right)$. The two dental morphs have a similar range of scores on PC I; however, the papilliform morph shows continuous variation, whereas the molariform morph shows a noticeable if not dramatic discontinuity between eight individuals with lower PC I scores and the rest of the sample. The small, separate clusters of molariform individuals in Figures 5 and 6 comprised the same individuals. To investigate the possibility that these separate clusters represent a narrow-bodied morph, I went back to the photographs of the fish and qualitatively classified each individual as either 'normal' or 'narrow-bodied', 


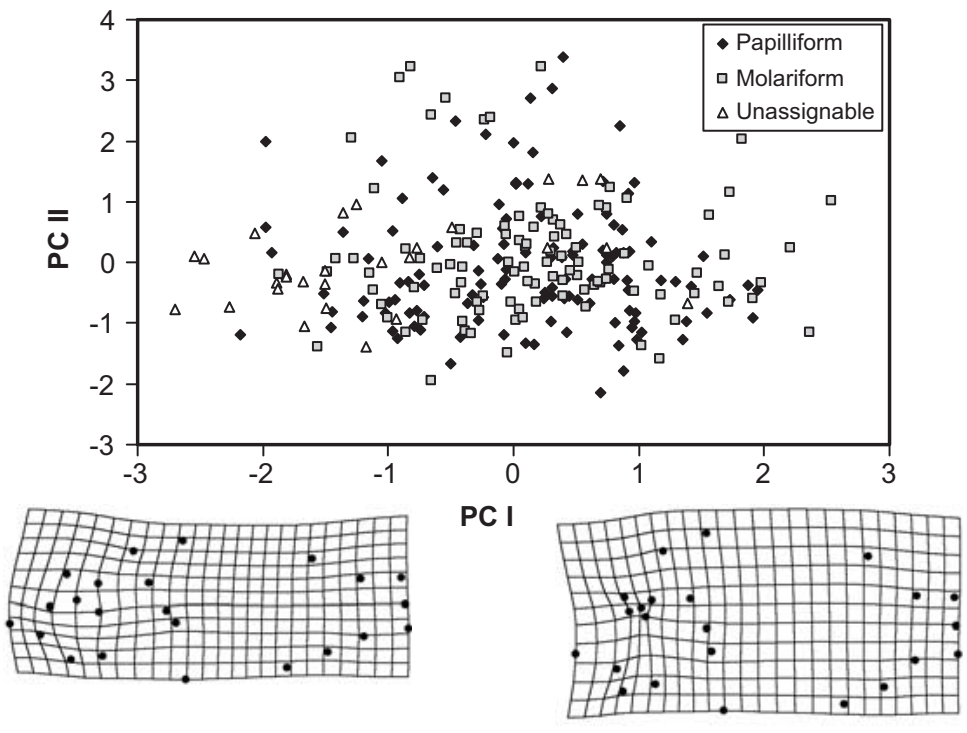

Figure 5. Scores on the first two principal components of Procrustes shape coordinates for the entire data set. Thin-plate spline deformation grids are shown for small (left) and large (right) individuals.

without knowledge of which cluster each individual fell in. The ones classified as 'narrow-bodied' corresponded to individuals in the small, distinct clusters. These individuals, it should be noted, come from multiple localities (and localities from which many 'normal' fish were collected) and cannot comprise a geographic variant. Two representative fish are shown in Figure 6; one with low PC I score and the other with high PC I score. These individuals illustrate the range of shape variability along the PC I axis, which is also illustrated with deformation grids (Figure 6). While both morphs encompass about the same range of shape variability, they exhibit different patterns within that range.

\section{Comparison with traditional morphometrics}

The measurement protocol used in the traditional morphometric analysis is shown in Figure 7(a). Analysis was performed on the entire data set to maintain the requirement for PCA that the number of individuals be greater than the number of variables. Similar to the results of my earlier traditional analysis (Trapani 2003; see also Figure 2(b)), the first component in these analyses accounted for $>97 \%$ of the variance, and is very highly correlated with size $\left(\mathrm{R}^{2}=0.9993\right.$ against $\mathrm{LCS}$; compare with $\mathrm{R}^{2}=0.7169$ in the geometric analysis and $\mathrm{R}^{2}=3.807 \times 10^{-10}$ in the geometric analysis of size-standardized data). PC II accounted for $<1 \%$ of variance in the traditional analyses, in contrast to around $10 \%$ in geometric analyses. Interestingly, PC II from the geometric (unstandardized) and traditional analyses were relatively highly correlated with one another $\left(R^{2}=0.7490\right.$ for the whole data set), indicating that analyses were picking up similar information along this component.

Of the linear measures that contribute most to PC II in the traditional analysis, many involve landmark 19 (see Figure 3). Interlandmark distances with the highest loadings are: 18-19 (0.236), 3-19 (0.216), 1-19 (0.204), and 17-19 (0.198). Most of these involve the length of the snout. Other distances with relatively high loadings are also in the head region, illustrating that the traditional analysis mainly picked up variation in this region. Interlandmark distances that might intuitively be expected to contribute highly to differences in body-form (i.e. 7-16, 10-14) did not load highly on this component in the traditional analysis $(-0.068$ and -0.033 , respectively).

Figure 7(b)-(d) shows plots of the first two principal components for the traditional, geometric, and size-standardized geometric analyses, respectively. In the traditional plot (Figure 7(b)), I have coded the eight individuals corresponding to the separate cluster of 'narrow-bodied' individuals in Figures 7(c) and (d) with a different symbol for ease of comparison. 

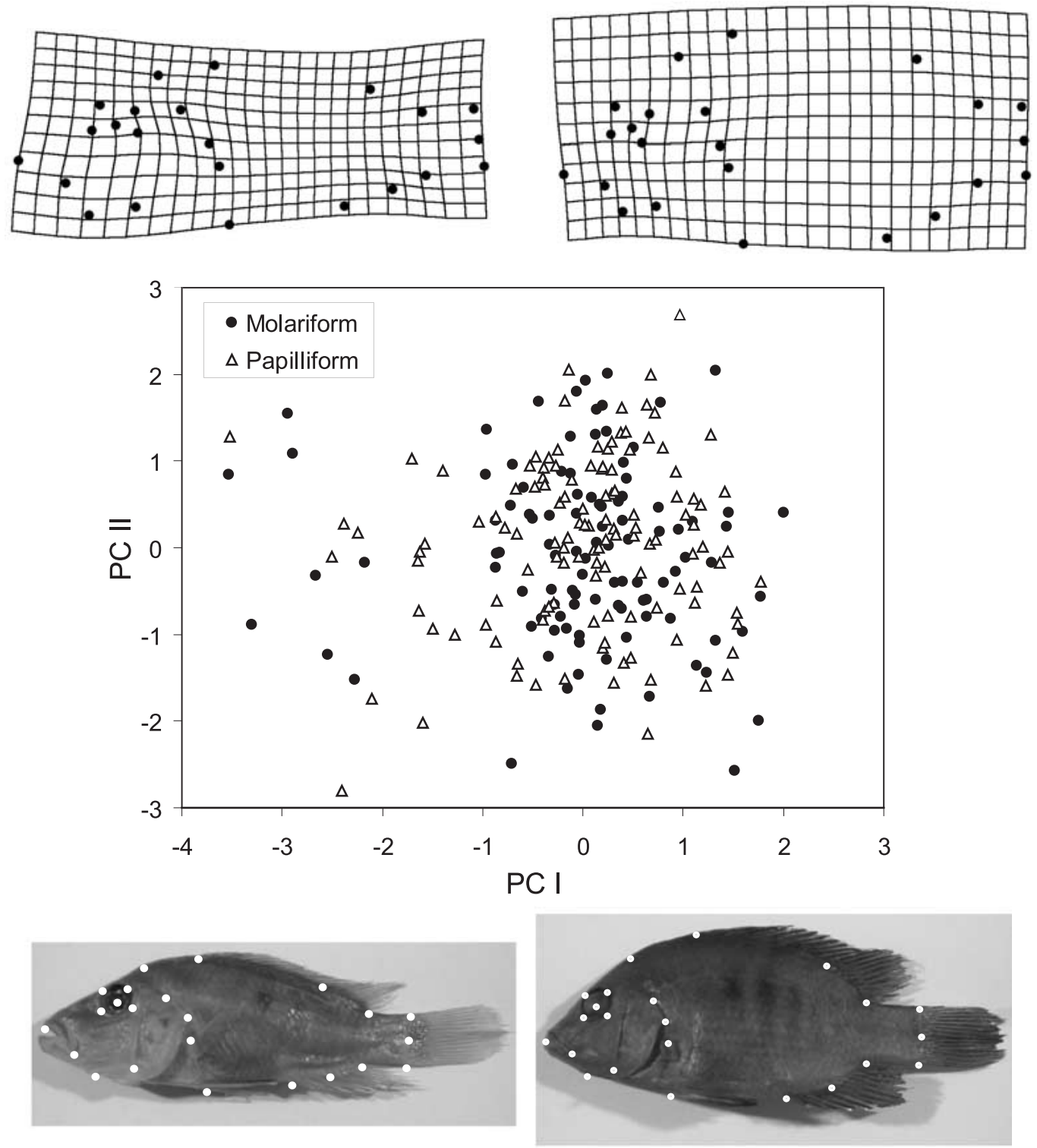

Figure 6. Principal component I and II scores for molariform and papilliform individuals standardized to mean size. Note the difference in the distribution along PC I, with continuous variation in papilliform individuals and a marked discontinuity in molariform individuals. Representative individuals with low and high PC I scores (bottom) as well as deformation grids (top) are shown on the plot to represent shape variation along that dimension.

\section{Discussion}

Many African cichlids thought to be separate biological species are difficult to distinguish using traditional molecular methods such as mtDNA (Kornfield
\& Smith 2000), though analyses using microsatellites have shown more promise at documenting differences at this level (Wilson et al. 2000, Markert et al. 2001). Cichlasoma minckleyi has yet to be incorporated into molecular systematic studies of Neotropical 

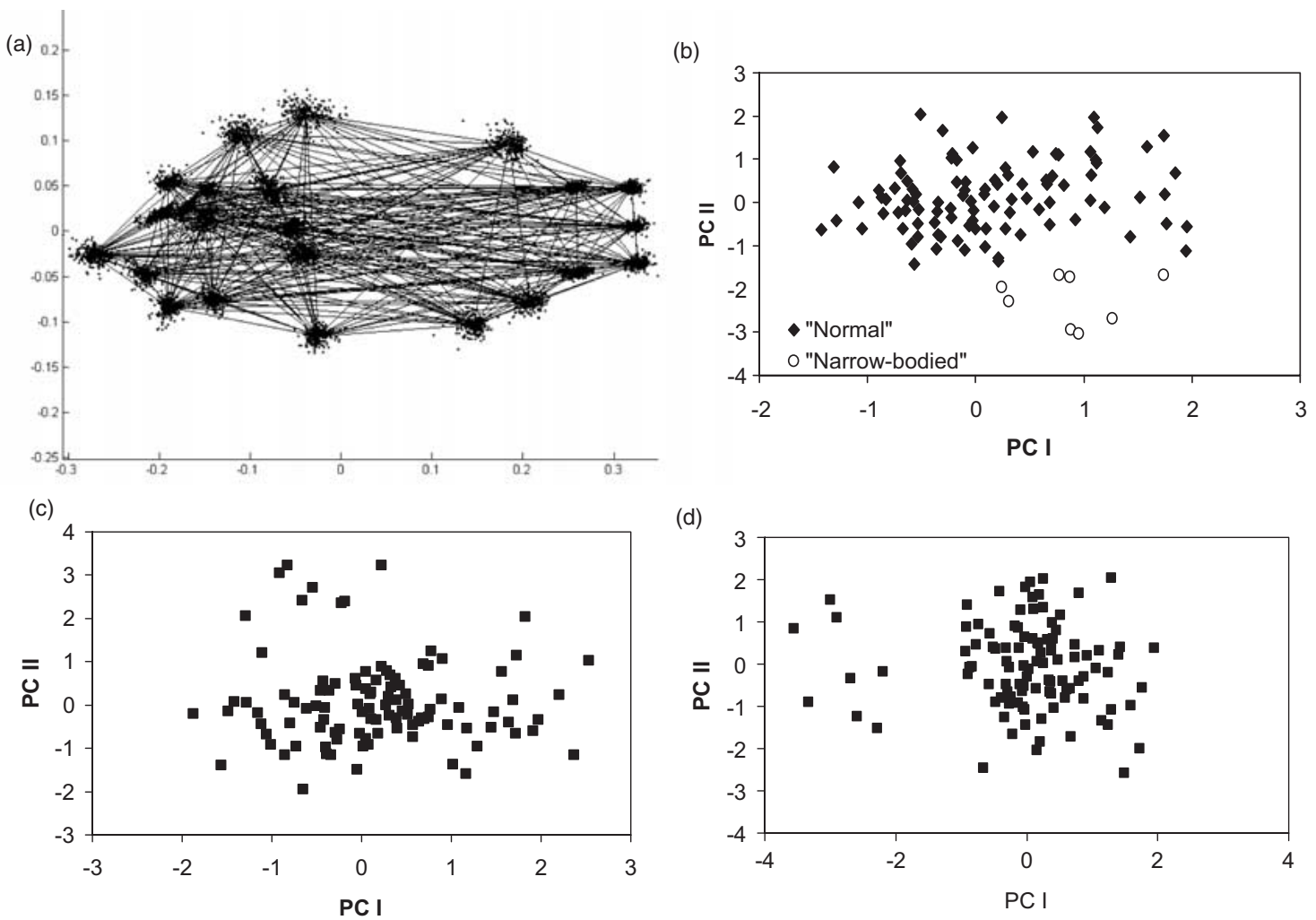

Figure 7. (a) Measurement protocol for traditional analysis performed using interlandmark distances including scatters of data around each landmark (Procrustes shape coordinates). Scores for molariform individuals on the first two principal components are shown for (b) the traditional data set, (c) the geometric analysis, and (d) the geometric analysis of size-standardized data.

cichlids (e.g., Roe et al. 1997), and lack of significant genetic differences (Kornfield \& Koehn 1975, Sage \& Selander 1975) between C. minckleyi dental morphs must therefore be interpreted cautiously. Additional caution is warranted because studies of biochemical differences between dental morphs did not take body-form variation into account. Likewise, studies showing nonassortative mating between dental morphs (Kornfield et al. 1982) also failed to explicitly account for body-form variation or to investigate viability of offspring of such matings. Hybridization between lineages can make distinguishing separate species from polymorphism difficult (Robinson \& Schluter 2000).

In this context, the lack of significant differences in body-form between papilliform and molariform individuals documented in this study corroborates the existence of a single species, especially given the high statistical power of geometric morphometric techniques. The results here largely agree with Kornfield \& Taylor's (1983) description of C. minckleyi, with the exception of their claim for a discrete polymorphism in body-form within the papilliform morph. However, while body morphology adds a compelling piece of evidence to the case for a single species, the only way to fully investigate the question of whether separate 'morphs' constitute biological species or not is with sets of controlled crosses.

Observed patterns of variability meet some but not all of the predictions laid out in the introduction. Previous studies have shown that body-form is often correlated with diet/foraging behavior (Toline \& Baker 1993, Winemiller et al. 1995) and trophic morphology (Ruber \& Adams 2001). However, despite pronounced differences in trophic morphology, molariform and papilliform $C$. minckleyi were not found to differ significantly in size, body shape, or allometric patterns. This may be explained by lack of habitat segregation. Both papilliform and molariform $C$. minckleyi have rather generalized diets and overlap considerably under normal conditions (Liem \& Kaufman 1984, personal 
observation; see also Robinson \& Wilson 1998). This overlap true of both diets and habitats, since snails and detritus are often co-localized in the Cuatro Cienegas basin (but see Swanson et al. 2003). Changes in pharyngeal trophic structures no doubt cause changes in adjacent anatomical structures (e.g., Smits et al. 1996, Schaack \& Chapman 2003), but in this case, perhaps because both morphs are foraging in the same environments, these effects are not apparent in external form.

Within each morph, variability in body-form corresponds to that predicted between piscivores and more generalized 'normal' fish. Although some of the landmarks in this study do not correspond exactly to the osteological features Liem (1978) described, the narrow-bodied molariform morph seems to possess many of these characteristic piscivorous features (Figure 6). However, it may also be worth noting that molariform pharyngeal teeth are not found in a 'typical' cichlid piscivore.

Perhaps the most interesting result of this study is the different pattern of body-form variability exhibited by each morph; specifically, papilliform individuals show a continuous distribution, whereas molariform individuals exhibit a discontinuity (Figure 6). Body-form in fishes may result from environmental (Meyer 1987, Bronmark \& Miner 1992, Robinson \& Parsons 2002), genetic (Toline \& Baker 1997), or a combination of inputs (Wimberger 1991, 1992, Robinson \& Wilson 1996). There are several possible explanations for differences in body-form variability between dental morphs; choosing between them hinges mainly on the issue of how genotype and environment combine to result in the body-form phenotype.

If body-form in C. minckleyi is primarily under genetic control (i.e. different genotypes produce different phenotypes), it may be that the specific genes involved differ between dental morphs. However, this seems unlikely given the observed nonassortative mating between dental morphs (Kornfield et al. 1982). Alternatively, the piscivorous molariform morph may constitute a separate biological species. Successful matings between narrow and deep-bodied individuals suggest this is not the case. (UMMZ collections contain preserved offspring from such a mating. However, it is not known whether either of the parents was molariform, and individuals are too small to assess whether they would be reproductively viable.) Postulating a separate species would also raise new questions about differences between dental morphs, as molariform individuals (excluding piscivores) would then seem more restricted morphologically than their papilliform conspecifics.

If body-form is primarily under environmental control (i.e. the same genotype can produce different phenotypes under different environmental or behavioral conditions), there are several more-likely hypotheses for why patterns of variation differ between dental morphs. If piscivorous feeding habits lead to development of a narrower-bodied phenotype, it may be that dental morphs utilize different behaviors and/or consume different prey fishes and thus exhibit different responses.

A second possibility involves the degree of specialization exhibited by individuals dental morphs who consume fish. While molariform cichlids can obtain two of their main food resources (detritus and snails) in the same habitat, papilliform cichlids cannot crush hard snail shells and must obtain alternative food sources elsewhere. This is reflected in the relative amounts of time the two morphs spend in various habitats (Cuatro Cienegas Earthwatch Group 1999). Since these data indicate that papilliform fish divide their time up more equally among more habitats, they may be able to consume fish opportunistically as they encounter them and remain relatively generalized in their diet. Molariform fish, in contrast, would need to disrupt their activity patterns to pursue a substantial number of fish, and would be more likely to become specialized piscivores if they add this component to their diet at all. Anecdotal evidence suggests that piscivorous cichlids engage in distinct prey-capture behaviors; specifically, hiding on the bottom and 'stalking' groups of prey fishes (frequently pupfishes). But no studies have been done to investigate differences between morphs in aspects of or time spent performing this behavior. Analysis of gut contents and laboratory experiments are additional ways of testing the hypotheses advanced here.

In addition, it is possible that polymorphism in the pharyngeal apparatus and variability in bodyform interact to constrain molariform individuals from developing morphologies intermediate between the narrow-bodied and normal ranges, or that natural selection acts against any individuals in this range. Finally, differences between dental morphs could be an artifact of sampling or small sample size. But this is unlikely because sample size is rather substantial (nearly 240 individuals assignable to body morph) and samples contain individuals collected at a number of different times from various localities within the Cuatro Cienegas Basin and from two different institutional collections. 
I suggest that there is an important environmental component to body-form in Cuatro Cienegas cichlids. Further elucidation of the specific environmental influences and identification of mechanisms generating the observed patterns of variability requires further study.

While traditional morphometrics does, to some degree, separate the two body-form morphs, it does not indicate discontinuity in variation. Geometric morphometrics makes the distinction clearer, and geometric analysis of size-standardized data does an even better job (Figure 7). This result is similar to results from other studies comparing geometric and traditional morphometric analyses of similar data (e.g., Birch 1997). Two reasons account for this difference. First, geometric morphometrics allow consideration of shape independent of scale (Bookstein 1991), and sizestandardization allows consideration of shape independent both of scale and allometry. Neither size nor shape are 'thrown out' in such analyses; they are simply parceled into components that can be considered independently of one another. Second, instead of analyzing restricted and often somewhat arbitrary sets of distance measures, geometric morphometrics analyzes covariances in landmark configurations (Bookstein 1991, 1996a). This adds shape information, and thus power, to the statistical analysis (Rohlf 1999).

\section{Acknowledgements}

I would like to thank F. Bookstein, D. Sheets, G. Smith, D. Swiderski and M. Zelditch for discussion and assistance with aspects of the morphometric analysis, P. Wilf for providing computing facilities, D. Nelson for assistance navigating the UMMZ collections, and M. Douglas and T. Dowling for a loan of ASU specimens. C. Badgley, F. Bookstein, K. Parsons, G. Smith, M. Zelditch, and two anonymous reviewers read and helped improve the manuscript. E. Carson, T. Dowling, D. Hendrickson, R.R. Miller, W.L. Minckley and J. Taylor are also to be thanked for aiding my thinking on some of these issues. I have been funded by a National Science Foundation Graduate Fellowship and Predoctoral Graduate Fellowship from Rackham Graduate School at the University of Michigan.

\section{References}

Abouheif, E. \& G.A. Wray. 2002. Evolution of the gene network underlying wing polyphenism in ants. Science 297 249-252.
Adams, D.C. \& D.J. Funk. 1997. Morphometric inferences on sibling species and sexual dimorphism in Neochlamisus bebbianae leaf beetles: Multivariate applications of the thinplate spline. Syst. Biol. 46: 180-194.

Albertson, R.C. \& T.D. Kocher. 2001. Assessing morphological differences in an adaptive trait: A landmark-based morphometric approach. J. Exp. Zool. 289: 385-403.

Birch, J.M. 1997. Comparing wing shape of bats: The merits of principal components analysis and relative warp analysis. J. Mammal. 78: 1187-1198.

Bookstein, F.L. 1989. 'Size and shape': A comment on semantics. Syst. Zool. 38: 173-180.

Bookstein, F.L. 1991. Morphometric Tools for Landmark Data, Cambridge University Press, New York. 435 pp.

Bookstein, F.L. 1996a. Biometrics, biomathematics and the morphometric synthesis. Bull. Math. Biol. 58: 313-365.

Bookstein, F.L. 1996b. Combining the tools of geometric morphometrics. pp. 131-151 In: L.F. Marcus et al. (ed.) Advances in Morphometrics, Plenum Press, New York.

Bookstein, F.L., B. Chernoff, R.L. Elder, J.M. Humphries, G.R. Smith \& R.E. Strauss. 1985. Morphometrics in Evolutionary Biology. Academy of Natural Sciences of Philadelphia Special Publication 15: 1-277.

Bronmark, C. \& J.G. Miner. 1992. Predator-induced phenotypical change in body morphology in crucian carp. Science 258 : 1348-1350.

Caldecutt, W.J. \& D.C. Adams. 1998. Morphometrics of trophic osteology in the threespine stickleback, Gasterosteus aculeatus. Copeia 1998: 827-838.

Clark, W.C. 1976. The environment and the genotype in polymorphism. Zool. J. Linn. Soc. 58: 255-262.

Cuatro Cienegas Earthwatch Group. 1999. Habitat use by Cichlasoma minckleyi, a polymorphic cichlid endemic to the Cuatro Cienegas basin of Coahuila, Mexico. http://www. utexas.edu/depts/tnhc/fish/cc-research /pub /earthwatch1999/ data/behavior/morph_behavior.html

Guill, J.M., C.S. Hood \& D.C. Heins. 2003. Body shape variation within and among three species of darters (Perciformes: Percidae). Ecol. Freshwat. Fish 12: 134-140.

Hegrenes, S. 2001. Diet-induced phenotypic plasticity of feeding morphology in the orangespotted sunfish, Lepomis humilis. Ecol. Freshwat. Fish 10: 35-42.

Hood, C.S. \& D.C. Heins. 2000. Ontogeny and allometry of body shape in the blacktail shiner, Cyprinella venusta. Copeia 2000: 270-275.

Humphries, J.M., F.L. Bookstein, B. Chernoff, G.R. Smith, R.L. Elder \& S.G. Poss. 1981. Multivariate discrimination by shape in relation to size. Syst. Zool. 30: 291-308.

Kornfield, I.L. \& R.K. Koehn. 1975. Genetic variation and speciation in New World cichlids. Evolution 29: 427-437.

Kornfield, I., D.C. Smith, P.S. Gagnon \& J.N. Taylor. 1982. The cichlid fish of Cuatro Cienegas, Mexico: Direct evidence of conspecificity among distinct trophic morphs. Evolution 36: 658-664.

Kornfield, I. \& P.F. Smith. 2000. African cichlid fishes: Model systems for evolutionary biology. Annu. Rev. Ecol. Syst. 31: 163-196.

Kornfield, I. \& J.N. Taylor. 1983. A new species of polymorphic fish, Cichlasoma minckleyi, from Cuatro Cienegas, Mexico (Teleostei: Cichlidae). Proc. Biol. Soc. Wash. 96: 253-269. 
LaBounty, J.F. 1974. Materials for the revision of cichlids from northern Mexico and southern Texas, U.S.A. (Perciformes: Cichlidae). Unpublished Ph.D. Dissertation. University Microfilms, Arizona State University. 120 pp.

Liem, K.F. 1978. Modulatory multiplicity in the functional repertoire of the feeding mechanism in cichlid fishes. I. Piscivores. J. Morph. 158: 323-360.

Liem, K.F. \& L.S. Kaufman. 1984. Intraspecific macroevolution: Functional biology of the polymorphic cichlid species Cichlasoma minckleyi. pp. 203-215. In: A.A. Echelle \& I. Kornfield (ed.) Evolution of Fish Species Flocks, University of Maine at Orono, Orono.

Lleonart, J., J. Salat \& G.J. Torres. 2000. Removing allometric effects of body size in morphological analysis. J. Theor. Biol 205: 85-93.

Markert, J.A., P.D. Danley \& M.E. Arnegard. 2001. New markers for new species: Microsatellite loci and the East African cichlids. Trends Ecol. Evol. 16: 100-107.

Meyer, A. 1987. Phenotypic plasticity and heterochrony in Cichlasoma managuense (Pisces, Cichlidae) and their implications for speciation in cichlid fishes. Evolution 41: 1357-1369.

Meyer, A. 1990. Morphometrics and allometry in the trophically polymorphic cichlid fish, Cichlasoma citrinellum: Alternative adaptations and ontogenetic changes in shape. J. Zool. 221: 237-260.

Meyer, A. 1993. Trophic polymorphisms in cichlid fish: Do they represent intermediate steps during sympatric speciation and explain their rapid adaptive radiation? pp. 257-266. In: J.H. Schroder, J. Bauer \& M. Schartl (ed.) Trends in Ichthyology: An International Perspective, Blackwell Scientific Publications, Oxford.

Minckley, W.L. 1969. Environments of the Bolsón of Cuatro Cienegas, Coahuila, Mexico. The University of Texas at El Paso Science Series 2: 1-65.

Minckley, W.L. 1984. Cuatro Cienegas fishes: Research review and a local test of diversity versus habitat size. Journal of the Arizona-Nevada Academy of Science 19: 13-21.

Monteiro, L.R. 1999. Multivariate regression models and geometric morphometrics: The search for causal factors in the analysis of shape. Syst. Biol. 48: 192-199.

Robinson, B.W. \& K.J. Parsons. 2002. Changing times, spaces, and faces: Tests and implications of adaptive morphological plasticity in the fishes of northern postglacial lakes. Can. J. Fish. Aquat. Sci. 59: 1819-1833.

Robinson, B.W \& D. Schluter. 2000. Natural selection and the evolution of adaptive genetic variation in northern freshwater fishes. pp. 65-94. In: T.A. Mousseau, B. Sinervo, \& J. Endler (ed.) Adaptive Genetic Variation in the Wild, Oxford University Press, Oxford.

Robinson, B.W. \& D.S. Wilson. 1996. Genetic variation and phenotypic plasticity in a trophically polymorphic population of pumpkinseed sunfish (Lepomis gibbosus). Evol. Ecol. 10: 631-652.

Robinson, B.W. \& D.S. Wilson. 1998. Optimal foraging, specialization, and a solution to Liem's Paradox. Amer. Nat. 151 223-235.

Robinson, B.W., D.S. Wilson, A.S. Margosian \& P.T. Lotito. 1993. Ecological and morphological differentiation of pumpkinseed sunfish in lakes without bluegill sunfish. Evol. Ecol. 7: 451-464.
Roe, K.J., D. Conkel \& C. Lydeard. 1997. Molecular systematics of Middle American cichlid fishes and the evolution of trophic types in 'Cichlasoma (Amphilophus)' and 'C. (Thorichthys)'. Mol. Phylog. Evol. 7: 366-376.

Rohlf, F.J. 1999. Shape statistics: Procrustes superimpositions and tangent spaces. J. Classif. 16: 197-223.

Rohlf, F.J. \& L.F. Marcus. 1993. A revolution in morphometrics. Trends Ecol. Evol. 8: 129-132.

Rosenzweig, M.L. 1978. Competitive speciation. Biol. J. Linn. Soc. 10: $275-289$.

Ruber, L. \& D.C. Adams. 2001. Evolutionary convergence of body shape and trophic morphology in cichlids from Lake Tanganyika. J. Evol. Biol. 14: 325-332.

Sage, R.D. \& R.K. Selander. 1975. Trophic radiation through polymorphism in cichlid fishes. Proc. Natl Acad. Sci. USA 71: 4669-4673.

Schaack, S. \& L.J. Chapman. 2003. Interdemic variation in the African cyprinid Barbus neumayeri: Correlations among hypoxia, morphology, and feeding performance. Can. J. Zool. 81: 430-440.

Schluter, D. 1996. Ecological causes of adaptive radiation. Amer. Nat. 148: S40-S64.

Smith, T.B. \& S. Skulason. 1996. Evolutionary significance of resource polymorphisms in fishes, amphibians, and birds. Annu. Rev. Ecol. Syst. 27: 111-133.

Smits, J.D., F. Witte \& F.G. Van Veen. 1996. Functional changes in the anatomy of the pharyngeal jaw apparatus of Astatoreochromis alluaudi (Pisces, Cichlidae), and their effects on adjacent structures. Biol. J. Linn. Soc. 59: 389-409.

Stephens, M.J. \& D.A. Hendrickson. 2001. Larval development of the Cuatro Cienegas cichlid, Cichlasoma minckleyi. Southwest. Nat. 46: 16-22.

Swanson, B.D., A.C. Gibb, J.C. Marks \& D.A. Hendrickson. 2003. Tropic polymorphism and behavioral differences decrease intraspecific competition in a cichlid, Herichthys minckleyi. Ecology 84: 1441-1446.

Taylor, D.W. \& W.L. Minckley. 1966. New world for biologists. Pac. Discovery 19: 18-22.

Thorpe, R.S. 1975. Quantitative handling of characters useful in snake systematics with particular reference to intraspecific variation in the ringed snake Natrix natrix (L.). Biol. J. Linn. Soc. 7: $27-43$.

Toline, C.A. \& A.J. Baker. 1993. Foraging tactic as a potential selection pressure influencing geographic differences in body shape among populations of dace (Phoxinus eos). Can. J. Zool. 71: $2178-2184$

Toline, C.A. \& A.J. Baker 1997. Evidence of a heritable component to body shape in the northern redbelly dace (Phoxinus eos). Can. J. Zool. 75: 1247-1253.

Trapani, J. 2003. Morphological variability in Cichlasoma minckleyi, the Cuatro Cienegas cichlid. J. Fish Biol. 62: 276-298.

Walker, J.A. 1996. Principal components of body shape variation within an endemic radiation of threespine stickleback. pp. 321-334. In: L.F. Marcus et al. (ed.) Advances in Morphometrics, Plenum Press, New York.

Webb, P.W. 1984. Body form, locomotion and foraging in aquatic vertebrates. Amer. Zool. 24: 107-120. 
Weiss, K.M. \& S.M. Fullerton. 2000. Phenogenetic drift and the evolution of genotype-phenotype relationships. Theor. Popul. Biol. 57: 187-195

West-Eberhard, M.J. 1986. Alternative adaptations, speciation, and phylogeny (a review). Proc. Natl Acad. Sci. USA 83: 1388-1392.

Wilson, A.B., K. Noack-Kunnmann \& A. Meyer. 2000. Incipient speciation in sympatric Nicaraguan crater lake cichlid fishes: Sexual selection versus ecological diversification. Proc. R. Soc. Lond. B 267: 2133-2141.

Wimberger, P.H. 1991. Plasticity of jaw and skull morphology in the Neotropical cichlids Geophagus brasiliensis and G. steindachneri. Evolution 45: 1545-1561.

Wimberger, P.H. 1992. Plasticity of fish body shape. The effects of diet, development, family and age in two species of Geophagus (Pisces: Cichlidae). Biol. J. Linn. Soc. 45: 197-218.
Wimberger, P.H. 1994. Trophic plasticity, polymorphisms, and speciation in vertebrates. pp. 19-43. In: D.J. Stouder, K. Fresh \& R.J. Feller (ed.) Theory and Application in Fish Feeding Ecology, University of South Carolina Press, Columbia.

Winemiller, K.O., L.C. Kelso-Winemiller \& A.L. Brenkert. 1995. Ecomorphological diversification and convergence in fluvial cichlid fishes. Environ. Biol. Fishes 44: 235-261.

Zelditch, M.L. \& W.L. Fink. 1995. Allometry and developmental integration of body growth in a piranha, Pygocentrus nattereri (Teleostei: Ostariophysi). J. Morph. 223: 341-355.

Zelditch, M.L., H.D. Sheets \& W.L. Fink. 2000. Spatiotemporal reorganization of growth rates in the evolution of ontogeny. Evolution 54: 1363-1371.

Zelditch, M.L., H.D. Sheets \& W.L. Fink. 2003. The ontogenetic dynamics of shape disparity. Palebiology 29: 139-156. 